\title{
Credit Cycles and Business Cycles
}

\author{
$\underline{\text { Costas Azariadis }}$
}

Unsecured firm credit moves procyclically in the United States and tends to lead gross domestic product, while secured firm credit is acyclical. Shocks to unsecured firm credit explain a far larger fraction of output fluctuations than shocks to secured credit. This article surveys a tractable dynamic general equilibrium model in which constraints on unsecured firm credit preclude an efficient capital allocation among heterogeneous firms. Unsecured credit rests on the value that borrowers attach to a good credit reputation, which is a forward-looking variable. Self-fulfilling beliefs over future credit conditions naturally generate endogenously persistent business cycle dynamics. A dynamic complementarity between current and future borrowing limits permits uncorrelated belief shocks to unsecured debt to trigger persistent aggregate fluctuations in both secured and unsecured debt, factor productivity, and output. The author shows that these sunspot shocks are quantitatively important, accounting for around half of output volatility. (JEL D92, E32)

Federal Reserve Bank of St. Louis Review, First Quarter 2018, 100(1), pp. 45-71.

https://doi.org/10.20955/r.2018.45-71

\section{OVERVIEW}

Two prominent characteristics of the business cycle are the high autocorrelations of credit and output time series and the strong cross-correlation between those two statistics. Understanding these correlations, without the help of large and persistent shocks to the productivity of financial intermediaries and to the technical efficiency of final goods producers, has been a long-standing goal of macroeconomic research and the motivation for the seminal contributions mentioned in Section 2. Is it possible that cycles in credit, factor productivity, and output are not the work of large and persistent productivity shocks that afflict all sectors of the economy simultaneously? Could these cycles instead come from shocks to people's confidence in the credit market?

This article gives an affirmative answer to both questions within an economy in which part of the credit firms require to finance investment is secured by collateral and the remainder

Costas Azariadis is a research fellow at the Federal Reserve Bank of St. Louis and a professor at Washington University in St. Louis. This essay is based on the longer and more technical article Azariadis, Kaas, and Yi (2016). The author thanks Steve Williamson and two anonymous referees for constructive comments.

(c) 2018, Federal Reserve Bank of St. Louis. The views expressed in this article are those of the author(s) and do not necessarily reflect the views of the Federal Reserve System, the Board of Governors, or the regional Federal Reserve Banks. Articles may be reprinted, reproduced, published, distributed, displayed, and transmitted in their entirety if copyright notice, author name(s), and full citation are included. Abstracts, synopses, and other derivative works may be made only with prior written permission of the Federal Reserve Bank of St. Louis. 
is based on reputation. The main contribution is to emphasize and quantify the role of reputational credit. Unsecured firm credit in the U.S. economy from 1981 to 2012 was quite important; it is strongly correlated with gross domestic product (GDP) and leads it by about a year. In our model, unsecured credit improves debt limits, facilitates capital reallocation, and helps aggregate productivity, provided that borrowers expect plentiful unsecured credit in the future. Favorable expectations of future debt limits increase the value of remaining solvent and on good terms with one's lenders. Widespread doubts, on the other hand, about future credit will lead to long-lasting credit tightening with severe macroeconomic consequences: Productive firms are unable to purchase or rent capital from unproductive ones, which end up owning too much capital. Aggregate productivity drops and GDP follows suit.

Total factor productivity (TFP) in this setting is sensitive to credit availability, and credit shocks drive TFP shocks. In this way, dynamic complementarity between current and future lending connects macroeconomic performance over time and endows one-time expectational impulses with long-lasting responses. A calibrated version of our economy matches well with the observed autocorrelations and cross-correlations of output, firm credit, and investment. Using the model to identify structural shocks to collateral credit, unsecured credit, and aggregate technology, I find that sunspot shocks to unsecured credit account for around half the variance in all major time series, while collateral shocks explain roughly one-third and technology shocks play a rather minor role. On the other hand, if the endogenous influence of sunspots on credit conditions is excluded a priori, the results show that too much output volatility would be incorrectly attributed to exogenous movements in aggregate technology-a standard result in the literature. I conclude that self-fulfilling and endogenously propagated credit shocks are quite important in U.S. business cycles.

\section{CONNECTIONS WITH THE LITERATURE}

Most citizens believe that credit availability is important for housing and other forms of investment as well as for job creation. If they are correct in this belief, there must be broadbased shocks to credit availability that real-world financial markets cannot easily overcome, as they would in the canonical Arrow-Debreu model of general equilibrium.

Starting with contributions of Bernanke and Gertler (1989) and Kiyotaki and Moore (1997), much of recent research is devoted to exploring how difficulties, or "frictions," in financial markets amplify and propagate disruptions to macroeconomic fundamentals, such as shocks to TFP or to monetary policy. More recently, and to some extent motivated by the events of the last financial crisis, several contributions argue that shocks to the financial sector itself may not only lead to severe macroeconomic consequences but can also contribute significantly to business cycle movements. For example, Jermann and Quadrini (2012) develop a model with collateral constraints, which they identify as residuals from aggregate time series of firm debt and collateral capital. Estimating a joint stochastic process for TFP and borrowing constraints, they find that both variables are highly autocorrelated and that financial shocks play an important role in business cycle fluctuations. $\underline{1}$ But what drives these shocks to financial conditions and to aggregate productivity? And what makes their responses so highly persistent? 
This paper focuses on unsecured firm credit, a variable that is overlooked in the literature but seems to be of key importance for answering these questions. I first document new facts about secured versus unsecured firm credit. Most strikingly, for the U.S. economy over the period 1981-2012, I find that unsecured debt is strongly procyclical, with some tendency to lead GDP, while secured debt is at best acyclical, thus not contributing to the well-documented procyclicality of total debt. This finding provides some challenge for business cycle theories based on the conventional view of Kiyotaki and Moore (1997) that collateralized debt amplifies and even generates the business cycle. When credit is secured by collateral, a credit boom is associated with not only a higher leverage ratio but also a higher value of the collateralized assets. Conversely, an economic slump is associated with deleveraging and a decrease in the value of collateral. This suggests that secured debt, such as mortgage debt, should be strongly correlated with GDP. But this is not what I find; to the contrary, based on firm-level data from Compustat and on aggregate data from the flow of funds accounts of the Federal Reserve Board, I show that it is the unsecured part of firm credit that strongly comoves with output.

The model is a standard stochastic growth model that comprises a large number of firms facing idiosyncratic productivity shocks. In each period, productive firms wish to borrow from their less-productive counterparts. Besides possibly borrowing against collateral, the firms exchange unsecured credit, which rests on reputation. Building upon Bulow and Rogoff (1989) and Kehoe and Levine (1993), I assume that a defaulting borrower is excluded from future credit for a stochastic number of periods. As in Alvarez and Jermann (2000), endogenous forward-looking credit limits prevent default. These credit limits depend on the value that a borrower attaches to a good reputation, which itself depends on future credit market conditions.

One contribution of this article is the tractability of this framework, which permits me to derive a number of insightful analytical results in Section 3. With standard and convenient specifications of preferences and technology, I characterize any equilibrium by one backwardlooking and one forward-looking equation (Result 1). With this characterization, I prove that unsecured credit cannot support first-best allocations, thereby extending related findings of Bulow and Rogoff (1989) and Hellwig and Lorenzoni (2009) to a growth model with idiosyncratic productivity (Result 2). I then show the existence of multiple stationary equilibria for a range of parameter configurations (Result 3 ). While there is always an equilibrium without unsecured credit, there can also exist one or two stationary equilibria with a positive volume of unsecured credit. One of these equilibria supports an efficient allocation of capital between firms, and another one features a misallocation of capital. The latter equilibrium is the one that provides the most interesting insights, since unsecured credit is traded and yet factor productivity falls short of the technology frontier. 2 I show that this equilibrium is always locally indeterminate and hence permits the existence of sunspot cycles fluctuating around the stationary equilibrium (Result 4). Moreover, output and credit respond persistently to a one-time sunspot shock.

One way to understand the role of expectations is to view unsecured credit like a bubble sustained by self-fulfilling beliefs, as has been argued by Hellwig and Lorenzoni (2009). Transitions from a "good" macroeconomic outcome with plenty of unsecured credit to a "bad" 
outcome with low volumes of unsecured credit can be triggered by widespread skepticism about the ability of financial markets to continue the provision of unsecured credit at the volume needed to support socially desirable outcomes, which is similar to the collapse of a speculative bubble. The emergence and the bursting of rational bubbles in financially constrained economies has received attention in a number of recent contributions, for example, Caballero and Krishnamurthy (2006); Kocherlakota (2009); Farhi and Tirole (2012); and Miao and Wang (2015).

This work is also related to a literature on sunspot cycles arising from financial frictions. In an early contribution, Woodford (1986) shows that a simple borrowing constraint makes infinitely lived agents behave like two-period-lived overlapping generations, so that endogenous cycles can occur with sufficiently strong income effects or with increasing returns to production (see, e.g., Benhabib and Farmer, 1999, for a survey). $\underline{3}$ Harrison and Weder (2013) introduce a production externality in a Kiyotake-Moore (1997) model and show that sunspots emerge for reasonable values of returns to scale. Benhabib and Wang (2013) show how the interaction between collateral constraints and endogenous markups can lead to indeterminacy for plausibly calibrated parameters. Liu and Wang (2014) find that the financial multiplier arising from credit constraints gives rise to increasing returns at the aggregate level, which facilitates indeterminacy.

Other recent contributions find equilibrium multiplicity and indeterminacy in endowment economies with limited credit enforcement under specific assumptions about trading arrangements (Gu et al., 2013) and about the enforcement technology (Azariadis and Kaas, 2013). Azariadis and Kaas (2016) study a related model with limited enforcement, also documenting equilibrium multiplicity. That article builds on a stylized model with linear production technologies, which is not suited for a quantitative analysis; it does not consider sunspot shocks and focuses on a multi-sector economy without firm-specific risk.

The rest of this article is organized as follows. The next section documents empirical evidence about secured and unsecured firm credit in the U.S. economy. In Section 4, I lay out the model framework; all equilibria by a forward-looking equation in the reputation values of borrowers; and derive my main results on equilibrium multiplicity, indeterminacy, and sunspot cycles. In Section 5, I extend the model in a few dimensions and conduct a quantitative analysis to explore the impacts of sunspot shocks and fundamental shocks on business cycle dynamics. Section 6 concludes.

\section{UNSECURED VERSUS SECURED FIRM DEBT}

This section summarizes evidence about firms' debt structure and its cyclical properties. I explore different firm-level data sets, covering distinct firm types, and relate the findings to evidence obtained from the flow of funds accounts. In line with previous literature, ${ }^{4}$ I show that unsecured debt constitutes a substantial part of firms' total debt and is typically lower for samples including smaller firms. Time-series variation, whenever available, further indicates that unsecured debt plays a much stronger role in aggregate output dynamics than debt secured by collateral. I first describe the data and the variables measuring unsecured and secured debt and then report business cycle features. 


\section{Figure 1}

\section{Share of Unsecured Debt in Total Debt for Firms in Compustat and Capital IQ}

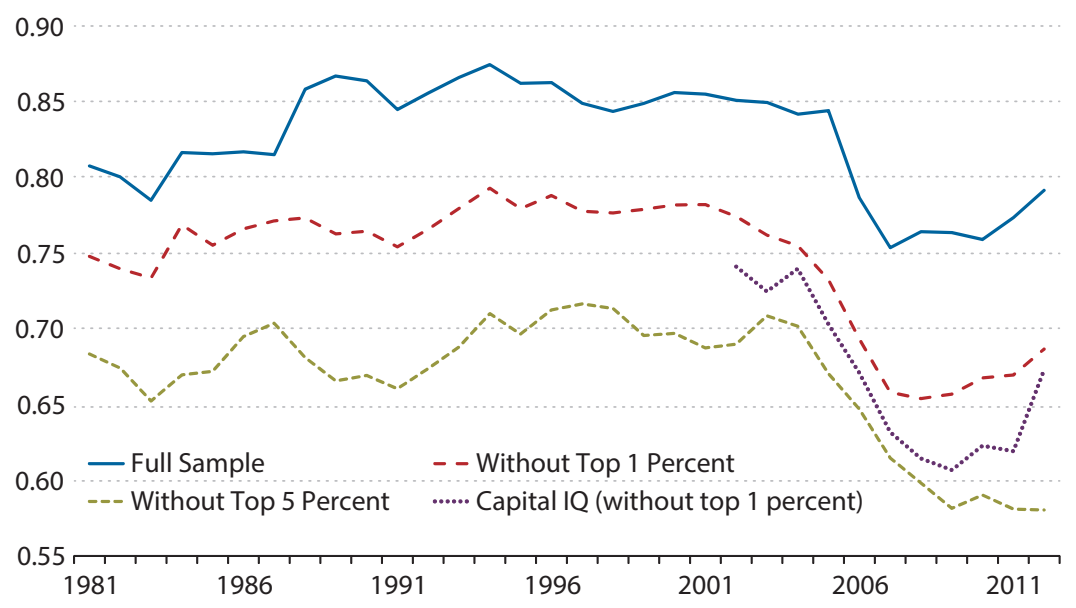

SOURCE: Compustat and Capital IQ.

\subsection{The Share of Unsecured Debt}

I start with the publicly traded U.S. firms covered by Compustat for the period 1981-2012 for which Compustat provides the item "dm: debt mortgages and other secured debt." In line with Giambona and Golec (2012), I use this item to measure secured debt, and I attribute the residual to unsecured debt. $\underline{5}$ The unsecured debt share is then defined as the ratio between unsecured debt and total debt. To clean the data, I remove financial firms and utilities, and I also remove those firm-year observations where total debt is negative, where item " $\mathrm{dm}$ " is missing, or where "dm" exceeds total debt. Since Compustat aggregates can easily be biased by the effect of the largest firms in the sample, I also consider subsamples where I remove the largest 1 percent or 5 percent of the firms by their asset size. To see the impact of the largest firms for unsecured borrowing, Figure 1 shows the series of the unsecured debt shares for the three samples obtained from Compustat. The role of the largest firms is quite important for the level of the unsecured debt share, although much less for the time-series variation. $\underline{6}$ The very biggest firms are likely to have better access to bond markets and hence borrow substantially more unsecured debt. Removing the largest 1 percent (5 percent) of firms, however, cuts out 45 percent ( 75 percent) of the aggregate firm debt in the sample. Interestingly, in the years prior to the financial crisis of 2007-08, the unsecured debt share fell substantially, as firms expanded their mortgage borrowing relatively faster than other types of debt, with some reversal after 2008 .

While Compustat covers public firms, the vast majority of U.S. firms are privately owned. To complement the above evidence, I also explore two data sets to obtain debt information for private firms. I first look at firms included in the database of Capital IQ, which is an affili- 
ate of Standard and Poor's that produces the Compustat database but covers a broader set of firms. Since coverage by Capital IQ is comprehensive only from 2002 onward, I report these statistics for the period 2002 to 2012. I clean the data in the same way as above and consider aggregates for the full sample (without financial firms and utilities) and for the sample without the 1 percent (5 percent) of the largest firms. Similar to the Compustat definition, I use the Capital IQ item "SEC: Secured Debt" and the residual "DLC + DLTT - SEC" to measure unsecured debt. The resulting unsecured debt shares show a similar cyclical pattern as those from Compustat during the same period. For visual clarity, Figure 1 includes only the Capital IQ series with the largest 1 percent of firms removed. Note, however, that including larger firms or removing the top 5 percent of firms has similar effects as for Compustat, though it does not affect the $U$-shaped cyclical pattern in the graph. Relative to the corresponding series in Compustat, firms in Capital IQ borrowed more secured debt in all years, which is possibly explained by the fact that these firms have lower market transparency and hence less access to bond markets. $\underline{\text { ? }}$

It is worth emphasizing that even the private firms included in the Capital IQ database are relatively large firms with some access to capital markets, so they are also not fully representative of the U.S. business sector. To obtain evidence on the debt structure of small firms, I use the data collected in the Survey of Small Business Finances (SSBF) conducted by the Board of Governors of the Federal Reserve System in 2003. Earlier surveys, conducted in 1987,1993 , and 1998, do not contain comparably comprehensive information on collateral requirements, so I cannot obtain evidence across time. Firms in this survey report their balances in different debt categories (and within each category for up to three financial institutions). For each loan, they report whether collateral is required and which type of collateral is used (real estate, equipment, or other). I aggregate across firms for each debt category and measure as secured debt all the loans for which collateral is required, while unsecured debt comprises credit card balances and all loans without reported collateral requirements. I minimally clean the data by only removing observations with zero or negative assets or equity. Table 1 shows the results of this analysis. While mortgages and credit lines constitute the largest debt categories of small firms, accounting for almost three-quarters of the total, significant fractions of the other three loan categories are unsecured. This results in an unsecured debt share of 19.3 percent for firms in the SSBF.

The evidence presented in Figure 1 and in Table 1 suggests that the unsecured debt share varies between about 20 percent (for the smallest firms) and 75 percent (for Compustat firms excluding the largest 1 percent). .9 To obtain a rough estimate for the average share of unsecured debt, I can further use the information in the flow of funds accounts, in which firm debt is categorized into several broad categories. About 95 percent of all credit market liabilities of non-financial firms are either attributed to mortgages (31 percent), loans (31 percent), or corporate bonds (33 percent). While mortgages are clearly secured and bonds are unsecured types of debt, the security status classification is ambiguous for loans. Among the non-mortgage loans in Table 1, around 30 percent are unsecured; this is a similar fraction as found in other studies. .0 Taken together, this suggests that around 45 percent $(\approx(0.33+0.31 \cdot 0.30) /(0.95))$ of the credit liabilities of non-financial firms is unsecured. In Section 4, I use an unsecured 


\section{Table 1}

Secured and Unsecured Debt in the SSBF (2003, percent)

\begin{tabular}{lcccc} 
Debt category & Share of debt & $\begin{array}{c}\text { Secured by } \\
\text { real estate/equipment }\end{array}$ & $\begin{array}{c}\text { Secured by } \\
\text { other collateral }\end{array}$ & Unsecured \\
\hline Credit cards & 0.6 & 0.0 & 0.0 & 100.0 \\
Lines of credit & 36.5 & 39.4 & 38.5 & 22.1 \\
Mortgages & 38.0 & 98.0 & 0.4 & 1.7 \\
Motor vehicle loans & 4.8 & 52.1 & 2.1 & 45.8 \\
Equipment loans & 6.5 & 62.0 & 1.7 & 36.4 \\
Other loans & 13.6 & 53.6 & 6.3 & 40.1 \\
Total & 100.0 & 65.4 & 15.2 & 19.3 \\
SOURCE: SSBF. & & & & \\
\hline
\end{tabular}

debt share of 50 percent as a calibration target.

Table 2

Relative Volatility and Comovement with Output (Compustat)

\begin{tabular}{lcccccccc} 
& \multicolumn{3}{c}{ Volatility relative to GDP } & & \multicolumn{2}{c}{ Correlation with GDP } \\
\cline { 2 - 3 } \cline { 6 - 8 } & Full sample & $\begin{array}{c}\text { Without } \\
\text { top 1\% }\end{array}$ & $\begin{array}{c}\text { Without } \\
\text { top 5\% }\end{array}$ & & Full sample & $\begin{array}{c}\text { Without } \\
\text { top 1\% }\end{array}$ & $\begin{array}{c}\text { Without } \\
\text { top 5\% }\end{array}$ \\
\hline Secured debt & 3.61 & 3.39 & 2.76 & & -0.15 & -0.05 & 0.15 \\
Unsecured debt & 4.19 & 3.73 & 4.43 & & 0.70 & 0.70 & 0.75 \\
SOURCE: Compustat. & & & & & & & \\
\hline
\end{tabular}

\subsection{Business Cycle Features}

I consider the time series from Compustat, deflate them by the price index for business value added, and linearly detrend the real series. 11 Table 2 reports the volatility of secured and unsecured debt (relative to output) as well as the contemporaneous correlations with output. Secured debt is weakly negatively correlated with GDP in the full sample; it becomes zero and weakly positive once I exclude the top 1 percent or 5 percent firms. In sharp contrast, unsecured debt is always strongly positively correlated with GDP. Thus, the well-known procyclicality of total firm credit is driven by the independent role of unsecured debt. Both secured and unsecured debt are about three to four times as volatile as output.

Figure 2 shows the detrended time series of unsecured and secured debt for the full sample over the observation period, together with GDP. While unsecured debt comoves strongly with output, secured debt is only weakly related. Between the mid-1990s and the mid-2000s, both debt series move together, but they exhibit quite different patterns before and after this period. Unsecured debt falls much more sharply than secured debt during all recessions except the one in 2007-09. 
Figure 2 Unsecured and Secured Debt for Compustat Firms, and GDP Multiplied by Factor Four
$(1981-2012)$

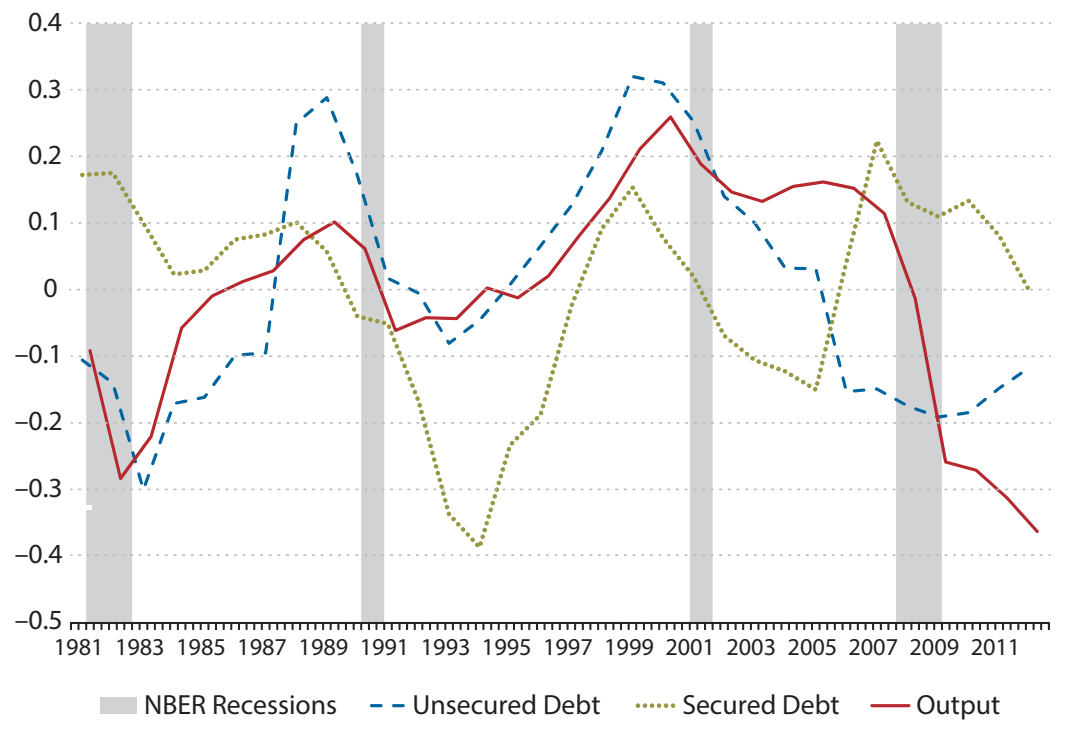

NOTE: Annual linearly detrended series. Gray bars indicate recessions as determined by the National Bureau of Economic Research (NBER).

SOURCE: Compustat.

\section{A MODEL OF UNSECURED FIRM CREDIT}

To capture the prominent role of unsecured firm credit, I develop in this section a macroeconomic model in which heterogeneous firms face idiosyncratic productivity shocks and borrow up to endogenous credit limits that preclude default in equilibrium. For expositional reasons, I present first a benchmark model featuring only unsecured credit, along with a fixed labor supply and i.i.d. firm-specific productivity shocks. I also do not consider aggregate shocks to economic fundamentals. All these assumptions will be relaxed in the next section. Tractability and the main theoretical findings are preserved in these extensions.

\subsection{The Setup}

The model has a continuum $i \in[0,1]$ of firms, each owned by a representative owner, and a unit mass of workers. At any time $t$, all individuals maximize expected discounted utility,

$$
\mathbb{E}_{t}(1-\beta) \sum_{\tau \geq t}^{\infty} \beta^{\tau-t} \ln \left(c_{\tau}\right)
$$

over future consumption streams. Workers are perfectly mobile across firms; they supply 1 unit of labor per period, have no capital endowment, and do not participate in credit markets. Firm owners hold capital and have no labor endowment. $\underline{12}$ They produce a consumption and 
investment good $y_{t}$ using capital $k_{t}^{\prime}$ and labor $\boldsymbol{\ell}_{t}$ with a common constant returns technology $y_{t}=\left(k_{t}^{\prime}\right)^{\alpha}\left(A \ell_{t}\right)^{1-\alpha}$. Aggregate labor efficiency $A$ is constant for now, which will be relaxed in Section 5 .

Firms differ in their ability to operate capital investment $k_{t}$. Some firms are able to enhance their invested capital according to $k_{t}^{\prime}=a^{p} k_{t}$; they are labeled "productive." The remaining firms are labelled "unproductive"; they deplete some of their capital investment such that $k_{t}^{\prime}=a^{u} k_{t}$. I assume that $a^{p}>1>a^{u}$ and write $\gamma \equiv a^{u} / a^{p}(<1)$ for the relative productivity gap. Productivity realizations are independent across agents and uncorrelated across time; firms are productive with probability $\pi$ and unproductive with probability $1-\pi$. Thus, a fraction $\pi$ of the aggregate capital stock $K_{t}$ is owned by productive firms in any period. Uncorrelated productivity simplifies the model; it also implies that the dynamics of borrowers' net worth do not propagate shocks as in Kiyotaki and Moore (1997) and Bernanke and Gertler (1989). At the end of a period, all capital depreciates at common rate $\delta$.

Timing within each period is as follows: First, firm owners observe the productivity of their business, then they borrow and lend in a centralized credit market at a gross interest rate $R_{t}$ and hire labor in a centralized labor market at wage $w_{t}$. Second, production takes place. Third, firm owners redeem their debt; they consume and save for the next period. All prices and credit constraints (as defined below) possibly depend on the realization of sunspot shocks.

In the credit market, productive firms borrow from unproductive firms, drawing on a short-term credit line that depends on their equity position and on a small array of macroeconomic variables. I rule out long-term loans and pre-determined interest rates that do not depend on current economic conditions. See Garriga et al. (2016) on the role of long-term nominal contracts. All credit is unsecured and is available only to borrowing firms with a clean credit history. If a firm decides to default in some period, the credit reputation deteriorates and the firm is banned from unsecured credit. $\underline{13}$ Defaulting firms can continue to operate their business; hence, they are able to produce or to lend their assets to other firms. ${ }^{14}$ Each period after default, the firm recovers its credit reputation with probability $\psi(\geq 0)$, in which case it regains full access to credit markets. $\underline{15}$

Since no shocks arrive during a credit contract (that is, debt is redeemed at the end of the period before the next productivity shock is realized), there exist default-deterring credit limits, defined similarly as in the pure exchange model of Alvarez and Jermann (2000). These limits are the highest values of credit that prevent default. Unsecured borrowing is founded on a borrower's desire to maintain a good credit reputation and continued access to future credit. Below I prove that credit constraints are necessarily binding in equilibrium (see Result 2).

Workers do not participate in the credit market and hence consume their labor income $w_{t}$ in every period. This assumption is not as strong as it may seem; in the steady-state equilibrium it only requires that workers are not permitted to borrow. This is because the steadystate gross interest rate $R$ satisfies $R<1 / \beta$ (see Corollary 1 ), which means that workers are borrowing constrained and do not desire to save. $\underline{16}$

At the beginning of the initial period $t=0$, a firm owner $i$ is endowed with capital (equity) $e_{0}^{i}$; hence, the initial equity distribution $\left(e_{0}^{i}\right)_{i \in[0,1]}$ is given. In any period $t \geq 0$, let $\theta_{t}$ denote the constraint on a borrower's debt-to-equity ratio in period $t$. This value is common for all bor- 
rowing firms because the value of solvency and default are proportional to the equity position of borrowers with a homothetic utility function, as shown below. It is endogenously determined to prevent default (cf. property (iii) of the following equilibrium definition). A productive firm $i$ entering the period with equity (capital) $e_{t}^{i}$ can borrow up to $b_{t}^{i}=\theta_{t} e_{t}^{i}$ and invest $k_{t}^{i}=e_{t}^{i}+b_{t}^{i}$. An unproductive firm lends out capital, so $b_{t}^{i}=\theta_{t} e_{t}^{i}$ and investment is $k_{t}^{i}=e_{t}^{i}+b_{t}^{i} \leq e_{t}^{i}$. Although the constraints $b_{t}^{i} \leq \theta_{t} e_{t}^{i}$ seem to resemble the collateral limits in the literature emanating from Kiyotaki and Moore (1997), I emphasize that $\theta_{t}$ here has very different features: It describes the size of an unsecured credit line, not the value of collateralizable equity. It is also a forward-looking variable that reacts to changes in credit market expectations.

The budget constraint for firm $i$ with capital productivity $a^{i} \in\left\{a^{p}, a^{u}\right\}$ reads as

$$
c_{t}^{i}+e_{t+1}^{i}=\left(a^{i} k_{t}^{i}\right)^{\alpha}\left(A \ell_{t}^{i}\right)^{1-\alpha}+(1-\delta) a^{i} k_{t}^{i}-w_{t} \ell_{t}^{i}-R_{t} b_{t}^{i} .
$$

I am now ready to define equilibrium.

Definition 1 A competitive equilibrium is a list of consumption, savings, and production plans for all firm owners, $\left(c_{t}^{i}, e_{t}^{i}, b_{t}^{i}, k_{t}^{i}, \ell_{t}^{i}\right)_{i \in[0,1], t \geq 0}$, conditional on realizations of idiosyncratic productivities and sunspot shock; consumption of workers, $c_{t}^{w}=w_{t}$; factor prices for labor and capital $\left(w_{t}, R_{t}\right)$; and debt-equity constraints $\theta_{t}$, such that the following occur:

(i) $\left(c_{t}^{i}, e_{t}^{i}, b_{t}^{i}, k_{t}^{i}, l_{t}^{i}\right)$ maximizes firm-owner $i$ 's expected discounted utility $\mathbb{E}_{t} \sum_{t \geq 0}^{\infty} \beta^{t} \ln \left(c_{t}^{i}\right)$, subject to the budget constrain (1) and credit constraints $b_{t}^{i} \leq \theta_{t} e_{t}^{i}$.

(ii) The labor market and the credit market clear in all periods $t \geq 0$ :

$$
\int_{0}^{1} \ell_{t}^{i} d i=1, \quad \int_{0}^{1} b_{t}^{i} d i=0 .
$$

(iii) If $b_{t}^{i} \leq \theta_{t} e_{t}^{i}$ is binding in problem (i), the firm-owner $i$ is exactly indifferent between debt redemption and default in period $t$, where default entails exclusion from credit for a stochastic number of periods with readmission probability $\psi$ in each period following default.

A typical equilibrium in this economy will lead all high-productivity firms to borrow their entire credit line and low-productivity firms to be indifferent between producing and lending. TFP in this situation is a weighted average of all individual TFP's, which reflects the misallocation of capital. Small credit lines will correspond to significant misallocation and low aggregate TFP. Generous credit lines will improve both TFP and GDP.

\subsection{Equilibrium}

The model permits a tractable description of individual choices. This is because individual firm's policies (i.e., borrowing/lending, saving, and employment) are all linear in the firm's equity position and independent of the firm's history, which in turn implies that these decisions can be easily aggregated. Furthermore, default incentives are also independent of the current size of the firm, which implies that all borrowing firms face the same constraint on their debt-to-equity ratio. Uncorrelated idiosyncratic productivities simplify the model further 
because all firms have the same chance to become productive in each period, so that the distribution of wealth is irrelevant. $\underline{17}$

Since firms hire labor to equate the marginal product to the real wage, all productive (unproductive) firms have identical capital-labor ratios; these are linked by a no-arbitrage condition implied by perfect labor mobility:

$$
\frac{k_{t}^{p}}{\ell_{t}^{p}}=\gamma \frac{k_{t}^{u}}{\ell_{t}^{u}} .
$$

With binding credit constraints, a fraction $z_{t} \equiv \min \left[1, \pi\left(1+\theta_{t}\right)\right]$ of the aggregate capital stock $K_{t}$ is operated by productive firms. It follows from (2) and labor market clearing that

$$
\frac{k_{t}^{p}}{\ell_{t}^{p}}=\frac{a_{t} K_{t}}{a^{p}} \leq K_{t}<\frac{a_{t} K_{t}}{a^{u}}=\frac{k_{t}^{u}}{\ell_{t}^{u}},
$$

where $a_{t} \equiv a^{p} z_{t}+a^{u}\left(1-z_{t}\right)$ is the average capital productivity. The gross return on capital for a firm with capital productivity $a^{s} \in\left\{a^{u}, a^{p}\right\}$ is then $a^{s} R_{t}^{*}$ with $R_{t}^{*} \equiv\left[1-\delta+\alpha A^{1-\alpha}\left(a_{t} K_{t}\right)^{\alpha-1}\right]$.

In any equilibrium, the gross interest rate cannot exceed the capital return of productive firms $a^{p} R_{t}^{*}$, and it cannot fall below the capital return of unproductive firms $a^{u} R_{t}^{*}$. Thus it is convenient to write $R_{t}=\rho_{t} a^{p} R_{t}^{*}$, with $\rho_{t} \in[\gamma, 1]$. When $\rho_{t}<1$, borrowers are credit constrained. In this case, the leveraged equity return $\left[1+\theta_{t}\left(1-\rho_{t}\right)\right] a^{p} R_{t}^{*}$ exceeds the capital return $a^{s} R_{t}^{*}$. Unproductive firms, on the other hand, lend out all their capital when $\rho_{t}>\gamma$; they only invest in their own inferior technology if $\rho_{t}=\gamma$. Therefore, credit market equilibrium is equivalent to the complementary-slackness conditions:

$$
\rho_{t} \geq \gamma, \quad \pi\left(1+\theta_{t}\right) \leq 1
$$

With this notation, the firm owner's budget constraint (1) simplifies to $e_{t+1}+c_{t}=R_{t} e_{t}$ when the firm is unproductive in $t$ and to $e_{t+1}+c_{t}=\left[1+\theta_{t}\left(1-\rho_{t}\right)\right] a^{p} R_{t}^{*} e_{t}$ when the firm is productive. It follows from logarithmic utility that every firm owner consumes a fraction $(1-\beta)$ of wealth and saves the rest.

To derive the endogenous credit limits, let $V_{t}(W)$ denote the continuation value of a firm owner with a clean credit reputation who has wealth $W$ at the end of period $t$, prior to deciding consumption and saving. These values satisfy the recursive equation $\underline{18}$ :

$$
\begin{aligned}
V_{t}(W) & =(1-\beta) \ln [(1-\beta) W] \\
& +\beta \mathbb{E}_{t}\left[\pi V_{t+1}\left(\left[1+\theta_{t+1}\left(1-\rho_{t+1}\right)\right] a^{p} R_{t+1}^{*} \beta W\right)+(1-\pi) V_{t+1}\left(R_{t+1} \beta W\right)\right] .
\end{aligned}
$$

The first term in this equation represents utility from consuming $(1-\beta) W$ in the current period. For the next period, $t+1$, the firm owner saves equity $\beta W$, which earns leveraged return $\left[1+\theta_{t+1}\left(1-\rho_{t+1}\right)\right] a^{p} R_{t+1}^{*}$ with probability $\pi$ and return $R_{t+1}$ with probability $1-\pi$. It follows that continuation $t+1$ values take the form $V_{t}(W)=\ln (W)+V_{t}$, where $V_{t}$ is independent of wealth, satisfying the recursive relation: 


$$
\begin{aligned}
V_{t} & =(1-\beta) \ln (1-\beta)+\beta \ln \beta \\
& +\beta \mathbb{E}_{t}\left[\pi \ln \left(\left[1+\theta_{t+1}\left(1-\rho_{t+1}\right)\right] a^{p} R_{t+1}^{*}\right)+(1-\pi) \ln \left(R_{t+1}\right)+V_{t+1}\right]
\end{aligned}
$$

For a firm owner with a default flag and no access to credit, the continuation value is $V^{d}(W)=\ln (W)+V^{d}$, where $V^{d}$ satisfies, analogously to equation (4), the recursion

$$
\begin{aligned}
V_{t}^{d} & =(1-\beta) \ln (1-\beta)+\beta \ln \beta \\
& +\beta \mathbb{E}_{t}\left[\pi \ln \left(a^{p} R_{t+1}^{*}\right)+(1-\pi) \ln \left(R_{t+1}\right)+V_{t+1}^{d}+\psi\left(V_{t+1}-V_{t+1}^{d}\right)\right]
\end{aligned}
$$

This firm owner cannot borrow in period $t+1$, so the equity return is $a^{p} R_{t+1}^{*}$ with probability $\pi$ and $R_{t+1}$ with probability $1-\pi$. At the end of period $t+1$, the credit reputation recovers with probability $\psi$, in which case the continuation utility increases from $V^{d}$ to $V_{t+1}$.

If a borrower has a clean credit reputation and enters period $t$ with equity $e_{t}$, the debtequity constraint $\theta_{t}$ makes him exactly indifferent between default and debt redemption if

$$
\ln \left(\left[1+\theta_{t}\left(1-\rho_{t}\right)\right] a^{p} R_{t}^{*} e_{t}\right)+V_{t}=\ln \left(a^{p} R_{t}^{*}\left(1+\theta_{t}\right) e_{t}\right)+V_{t}^{d} .
$$

Here the right-hand side is the continuation value after default: The firm owner invests $\left(1+\theta_{t}\right) e_{t}$, earns return $a^{p} R_{t}^{*}$, and does not redeem debt. The left-hand side is the continuation value under solvency, where the borrower earns the leveraged equity return $\left[1+\theta_{t}\left(1-\rho_{t}\right)\right] a^{p} R_{t}^{*}$.

Defining $v_{t} \equiv V_{t}-V^{d} \geq 0$ as the value of reputation, this equation can be solved for the default-deterring constraint on the debt-to-equity ratio:

$$
\theta_{t}=\frac{e^{v_{t}}-1}{1-e^{v_{t}}\left(1-\rho_{t}\right)}
$$

This constraint is increasing in the reputation value $v_{t}$ : A greater expected payoff from access to unsecured credit makes debt redemption more valuable, which relaxes the self-enforcing debt limit. In the extreme case when the reputation value is zero, unsecured credit cannot be sustained so that $\theta_{t}=0$.

Using (4) and (5), reputation values satisfy the recursive identity:

$$
\begin{aligned}
v_{t} & =\beta \mathbb{E}_{t}\left[\pi \ln \left(1+\theta_{t+1}\left(1-\rho_{t+1}\right)\right)+(1-\psi) v_{t+1}\right] \\
& =\beta \mathbb{E}_{t}\left[\pi \ln \left(\frac{\rho_{t+1}}{1-e^{v_{t+1}}\left(1-\rho_{t+1}\right)}\right)+(1-\psi) v_{t+1}\right] .
\end{aligned}
$$

I summarize this equilibrium characterization as follows:

Result 1 Any solution $\left(\rho_{t}, \theta_{t}, v_{t}\right)_{t \geq 0}$ to the system of equations (3), (6), and (7) gives rise to a competitive equilibrium with interest rates $R_{t}=\rho_{t} a^{p} R_{t}^{*}$, capital returns $R_{t}^{*}=1-\delta+\alpha A^{1-\alpha}\left(a_{t} k_{t}\right)^{\alpha-1}$, and average capital productivities $a_{t}=a^{u}+\left(a^{p}-a^{u}\right) \cdot \min \left[1, \pi\left(1+\theta_{t}\right)\right]$. The capital stock evolves according to 


$$
K_{t+1}=\beta\left[(1-\delta)+\alpha A^{1-\alpha}\left(a_{t} K_{t}\right)^{\alpha-1}\right] a_{t} K_{t} .
$$

An implication of this result is that any equilibrium follows two dynamic equations: the backward-looking dynamics of aggregate capital, equation (8), and the forward-looking dynamics of reputation values, equation (7), or, equivalently, equation (9) below. The latter identity is independent of the aggregate state $K_{t}$ and hence permits a particularly simple equilibrium analysis.

Using Result 1, I obtain two immediate results. First, an equilibrium with no unsecured credit always exists ( $v_{t}=0, \theta_{t}=0$, and $\rho_{t}=\gamma$ in all periods). Intuitively, if there is no value to reputation, any borrower prefers to default on unsecured credit so that debt limits must be zero. Second, I show that constraints on unsecured credit are necessarily binding. This is in line with earlier results by Bulow and Rogoff (1989) and Hellwig and Lorenzoni (2009), who show that the first-best $\frac{19}{}$ cannot be implemented by limited enforcement mechanisms that ban defaulting agents from future borrowing but not from future lending. It differs decisively from environments with two-sided exclusion, as in Kehoe and Levine (1993) and Alvarez and Jermann (2000), where first-best allocations can be sustained with unsecured credit under certain circumstances. $\underline{20}$ The intuition for this result is as follows: If borrowers were unconstrained, the interest rate would coincide with the borrowers' capital return. Hence, there would be no leverage gain and access to credit would have no value. In turn, every borrower would default on an unsecured loan, no matter how small. I summarize this finding as follows:

Result 2 Any equilibrium features binding borrowing constraints. Specifically, given any time and history, there exists some future time and continuation history in which the borrowing constraint is binding.

It follows immediately that the equilibrium interest rate is smaller than the rate of time preference.

Corollary 1 In any steady-state equilibrium, $R<1 / \beta$.

\subsection{Multiplicity and Cycles}

Although borrowers must be constrained, the credit market may nonetheless be able to allocate capital efficiently. In particular, when the reputation value $v_{t}$ is sufficiently large, credit constraints relax and the interest rate exceeds the capital return of unproductive firms who then lend out all their capital. Formally, when $v_{t}$ exceeds the threshold value,

$$
\bar{v}=\ln \frac{1}{1-\gamma(1-\pi)}>0,
$$

the equilibrium conditions (3) and (6) are solved by $\theta_{t}=(1-\pi) / \pi$ and $\rho_{t}=\left[1-e^{-v_{t}}\right] /(1-\pi)>\gamma$. Conversely, when $v_{t}$ falls short of $v$, credit constraints tighten, the interest rate equals the capital return of unproductive firms $\left(\rho_{t}=\gamma\right)$, who are then indifferent between lending out capital or investing in their own technology, so that some capital is inefficiently allocated. I can use this insight to rewrite the forward-looking equation (7) as 


$$
v_{t}=\mathbb{E}_{t} f\left(v_{t+1}\right)
$$

with

$$
f(v)=\left\{\begin{array}{l}
\beta(1-\psi) v+\beta \pi \ln \left[\frac{\gamma}{1-e^{v}(1-\gamma)}\right], \text { if } v \in[0, \bar{v}], \\
\beta(1-\pi-\psi) v+\beta \pi \ln (1 / \pi), \quad \text { if } v \in\left[\bar{v}, v_{\max }\right] .
\end{array}\right.
$$

Here $v=v_{\max }=\ln (1 / \pi)$ is the reputation value, where the interest rate reaches $\rho=1$ and borrowers are unconstrained. It is straightforward to verify that $f$ is strictly increasing if $\pi+\psi<1$, convex in $v<\bar{v}$, and it satisfies $f(0)=0, f(\bar{v})>\bar{v}$ if $\gamma$ is small enough, and $f\left(v_{\max }\right)<v_{\max }$. This reconfirms that the absence of unsecured credit $(v=0)$ is a stationary equilibrium. Depending on economic fundamentals, there can also exist one or two steady states exhibiting positive trading of unsecured credit. Panel A of Figure 3 shows a situation in which function $f$ has three intersections with the 45 degree line: $v=0, v^{*} \in(0, \bar{v})$, and $v^{* *} \in\left(\bar{v}, v_{\max }\right)$ The steady states at $v=0$ and at $v^{*}$ have inefficient capital allocation, whereas capital is efficiently allocated at $v^{* *}>\bar{v}$. Panel B of Figure 3 shows a possibility with only two steady states, at $v=0$ and at $v^{* *}>\bar{v}$. A third possibility (not shown in the figure) is that $v=0$ is the unique steady state, so that unsecured credit is not enforceable. The following result describes how the set of stationary equilibria changes as the productivity ratio $\gamma=a^{u} / a^{p}$ varies:

Result 3 For all parameter values $(\beta, \pi, \psi, \gamma)$, there exists a stationary equilibrium without unsecured credit and with inefficient capital allocation. In addition, there are threshold values $\gamma_{0}, \gamma_{1} \in(0,1)$ with $\gamma_{0}<\gamma_{1}$ for the productivity ratio $\gamma$ such that

(i) for $\gamma \in\left(\gamma_{0}, \gamma_{1}\right)$, there are two stationary equilibria with unsecured credit: one at $v^{*} \in(0, \bar{v})$ with inefficient capital allocation and one at $v^{* *} \in\left(\bar{v}, v_{\max }\right)$ with efficient capital allocation;

(ii) for $\gamma \leq \gamma_{0}$, there exists a unique stationary equilibrium with unsecured credit and efficient capital allocation at the reputation value $v^{* *} \in\left(\bar{v}, v_{\max }\right)$; and

(iii) for $\gamma>\gamma_{1}$, there is no stationary equilibrium with unsecured credit.

For small enough idiosyncratic productivity fluctuations $\gamma>\gamma_{1}$, unsecured credit is not enforceable, because firm owners value participation in credit markets too little. Conversely, for larger idiosyncratic shocks, exclusion from future credit is a sufficiently strong threat so that unsecured credit is enforceable without commitment. When idiosyncratic productivity shocks are sufficiently dispersed, the unique steady state with unsecured credit has an efficient factor allocation, while for intermediate values of $\gamma$, a third equilibrium emerges with unsecured credit and some misallocation of capital.

The explanation for equilibrium multiplicity is a dynamic complementarity between endogenous credit constraints, which are directly linked to reputation values. Borrowers' expectations of future credit market conditions affect their incentives to default now, which in turn determine current credit constraints. If future constraints are tight, the payoff of a clean credit reputation is modest so that access to unsecured credit has low value. In turn, 
Figure 3

Steady States at $v=0, v^{*} v^{* *}$
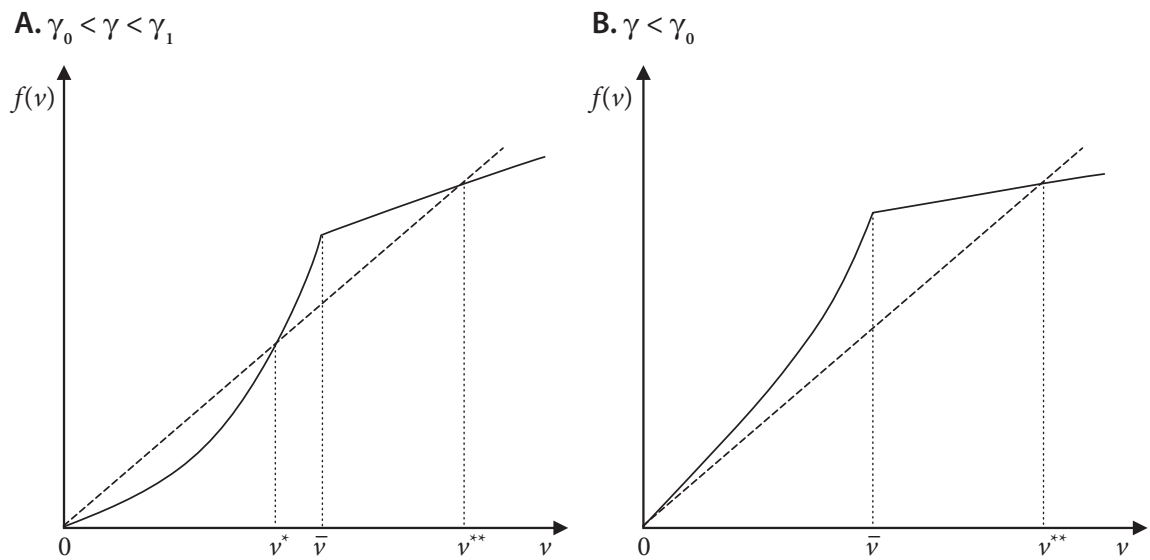

current default-deterring credit limits must be small. Conversely, if borrowers expect future credit markets to work well, a good credit reputation has high value, which relaxes current constraints.

As Figure 3 shows, multiplicity follows from a specific nonlinearity between expected and current reputation values. To understand this nonlinearity, it is important to highlight the different impacts of market expectations on borrowing constraints and on interest rates. In the inefficient regime $v \leq \bar{v}$, improvements in credit market expectations relax credit constraints without changes in the interest rate, which leads to particularly large gains from participation and hence to a strong impact on the current value of reputation. Conversely, if $v>\bar{v}$, beliefs in better credit conditions also raise the interest rate, which dampens the positive effect and hence mitigates the increase in the current reputation value.

Even when unsecured credit is available and possibly supports efficient allocations of capital, that efficiency rests on the confidence of market participants in future credit market conditions. When market participants expect credit constraints to tighten rapidly, the value of reputation shrinks over time, which triggers a self-fulfilling collapse of the market for unsecured credit. For instance, if $\gamma<\gamma_{0}$, the steady state at $v^{* *}$ is determinate and the one at $v=0$ is indeterminate; see Panel B of Figure 3. That is, there exists an infinity of nonstationary equilibria $v_{t}=f\left(v_{t+1}\right) \rightarrow 0$ where the value of reputation vanishes asymptotically. These equilibria are mathematically similar to the bubble-bursting equilibria in overlapping-generation models or in Kocherlakota (2009). If $\gamma \in\left(\gamma_{0}, \gamma_{1}\right)$, the two steady states at $v=0$ and at $v^{* *}$ are determinate, whereas the one at $v^{*}$ is indeterminate. In that situation, a self-fulfilling collapse of the credit market would be described by an equilibrium with $v_{t} \rightarrow v^{*}$, where a positive level of unsecured credit is still sustained in the limit. In both of these events, a one-time belief shock can lead to a permanent collapse of the credit market. But in the latter case, indeterminacy also permits stochastic business cycle dynamics driven by self-fulfilling beliefs (sunspots). Sunspot fluctu- 
ations vanish asymptotically if $\gamma<\gamma_{0}$, but they give rise to permanent volatility around the indeterminate steady state $v^{*}$ if $\gamma \in\left(\gamma_{0}, \gamma_{1}\right)$.

Result 4 Suppose that $\gamma \in\left(\gamma_{0}, \gamma_{1}\right)$, as defined in Result 3. Then there exist sunspot cycles featuring permanent fluctuations in credit, output, and TFP.

The dynamic complementarity between current and future endogenous credit constraints not only creates expectations-driven business cycles, it also generates an endogenous propagation mechanism: Because of $f^{\prime}\left(v^{*}\right)>1$, a one-time belief shock in period $t$ triggers a persistent adjustment dynamic of reputation values $v_{t+k}$ (and thus of credit, investment, and output) in subsequent periods. Intuitively, a self-fulfilling boom (slump) in unsecured credit in period $t$ can emerge only if the boom (slump) is expected to last for several periods.

Corollary 2 A one-time sunspot shock $\varepsilon_{t}>0\left(\varepsilon_{t}<0\right)$ in period t induces a persistent positive (negative) response of firm credit and output.

Although an endogenous propagation mechanism is not a necessary feature of any sunspot model, it tends to be associated with a large class of neoclassical models with local indeterminacy, such as the one in Benhabib and Farmer (1994). Local indeterminacy introduces additional state variables that tend to generate endogenous propagation mechanisms. The model differs from other sunspot models in that it uses borrower reputation as an additional state variable. The difference this makes is that sunspots are tied specifically to confidence in credit markets. I show in the next section that self-fulfilling beliefs in future credit conditions can indeed generate output fluctuations broadly similar to the data.

\section{QUANTITATIVE ANALYSIS}

The previous section demonstrates how self-fulfilling belief shocks can generate procyclical responses of unsecured credit, with potentially sluggish adjustment dynamics. In this section, I introduce some additional features to this model and calibrate it to the U.S. economy in order to examine the business cycle features of sunspot shocks as well as of fundamental shocks.

\subsection{Model Extension}

I extend the model in three directions. First, I include a variable labor supply. Second, I allow firms to issue debt secured by collateral. Third, I introduce aggregate fundamental shocks

to technology and to firms' collateral capacity.
$\quad$ Specifically, I modify workers' period utility to $\ln \left(C_{t}-\frac{\varphi}{1+\varphi} L_{t}^{(1+\varphi) / \varphi}\right)$, where $L_{t}$ is the labor supply and $\varphi$ is the Frisch elasticity. Regarding secured borrowing, I assume that a fraction $\lambda_{t}<1$ of a firm's end-of-period assets can now be recovered by creditors in a default event, instead of no recovery at all as in Section 4 . Since all firms can pledge collateral to their creditors, the relevant outside option of a defaulter is the exclusion from unsecured credit while retaining access to collateralized credit. As before, all credit is within the period and no default occurs in equilibrium, which implies that secured and unsecured credit carry the same interest rate $R_{t}$. Besides sunspot shocks, I allow for shocks to $\lambda_{t}$ and to aggregate labor efficiency $A_{t}$. 
The first type of shock directly affects the tightness of borrowing constraints, much like the financial shocks considered by Jermann and Quadrini (2012). Shocks to labor efficiency account for those movements in aggregate output that are not generated by the endogenous response of aggregate productivity to changes in the allocation of capital.

All productive firms in period $t$ can borrow secured credit up to the debt-equity limit $\theta_{t}^{s}$, which is determined from $R_{t} \theta_{t}^{s}=\lambda_{t} a^{p} R_{t}^{*}\left(1+\theta_{t}^{s}\right)$. For each unit of equity, the firm borrows $\theta_{t}^{s}$ so that a fraction $\lambda_{t}$ of the end-of-period assets $a^{p} R_{t}^{*}\left(1+\theta_{t}^{s}\right)$ fully protect the lenders who provide secured credit. On top of that, firms can borrow unsecured credit up to the endogenous debt-equity limit $\theta_{t}^{u}$. This extended model leads to the following constraint on the total debtto-equity ratio $\theta_{t}=\theta_{t}^{s}+\theta_{t}^{u}$, which precludes default:

$$
\theta_{t}=\frac{e^{v_{t}}-1+\lambda_{t}}{1-\lambda_{t}-e^{v_{t}}\left(1-\rho_{t}\right)}
$$

where $v_{t}$ is again the value of reputation, that is, the utility benefit of a clean credit reputation, and $\rho_{t}=R_{t} /\left(a^{p} R_{t}^{*}\right)$. This relation extends equation (6) to the case where some assets can be collateralized. One implication of equation (10) is that an exogenous reduction in collateral borrowing, of the type that may have triggered the 2007-09 Great Recession when housing prices dropped, will lead to a decline in total borrowing because unsecured borrowing does not expand fast enough to counteract the contraction in collateral. Observe that all borrowing must be secured; that is, $\theta_{t}=\theta_{t}^{s}$ if reputation has no value $\left(v_{t}=0\right)$. If $v_{t}>0$, borrowing in excess of $\theta_{t}^{s}$ is unsecured. Note, however, that the share $\lambda_{t}$ of the unsecured debt obligation $R_{t} \theta_{t}^{u}$ could be recovered if a firm opted for default. This is certainly a realistic feature since bond holders, for example, can recover a substantial fraction of their assets after a default. I also generalize equation (9) to a forward-looking equation:

$$
v_{t}=\mathbb{E}_{t} f\left(v_{t+1}, \lambda_{t+1}\right) .
$$

Therefore, I obtain a similar dichotomy as before: The dynamics of reputation values is independent of the capital stock, labor market variables, and technology shocks. I also confirm that, for specific parameter constellations, a steady state with unsecured credit and inefficient capital allocations exists; I choose this equilibrium for the calibration of model parameters. $\underline{21}$ This steady state is again indeterminate, so self-fulfilling belief shocks impact the dynamics of unsecured credit.

\subsection{Calibration}

I calibrate this model to the U.S. economy, choosing parameters so that the indeterminate steady-state equilibrium matches suitable long-run properties. The calibration targets correspond to statistics obtained for the U.S. business sector in the period 1981-2012. As the best available data source on unsecured versus secured credit is available at annual frequency, I calibrate the model annually and set $\delta, \alpha$, and $\beta$ in a standard fashion to match plausible values of capital depreciation, factor income shares, and the capital-output ratio, respectively. $\underline{22}$ The Frisch elasticity is set to $\varphi=1$. I normalize average capital productivity in steady state to $a=1$ 
Table 3

Parameter Choices

\begin{tabular}{lll} 
Parameter & Value & Explanation/Target \\
\hline$\delta$ & 0.078 & Depreciation rate \\
$\alpha$ & 0.3 & Capital income share \\
$\beta$ & 0.89 & Capital-output ratio \\
$\varphi$ & 1 & Frisch elasticity \\
$\psi$ & 0.1 & 10 -year default flag \\
$\pi$ & 0.18 & Share of productive firms (credit volume) \\
$\lambda$ & 0.43 & Recovery parameter (unsecured debt share) \\
$a^{u}$ & 0.779 & Lowest productivity (debt-to-equity ratio $\theta=3$ ) \\
$a^{p}$ & 1.080 & Highest productivity (normalization $a=1)$
\end{tabular}

and steady-state labor efficiency to $A=1$. I set the exclusion parameter $\psi=0.1$ so that a defaulting firm owner has difficulty obtaining unsecured credit for 10 years after default. $\underline{23} \mathrm{I}$ choose the remaining parameters $\pi, \lambda$, and $a^{u}$ to match the following three targets $\frac{24}{}$ : (i) credit to nonfinancial firms is 82 percent of annual GDP; (ii) the debt-to-equity ratio of constrained firms is $\theta=3$; and (iii) unsecured credit is 50 percent of total firm credit. $\underline{25}$ Given that this model has a two-point distribution of firm productivity (and hence of debt-to-equity ratios), the choice of target (ii) is somewhat arbitrary. I also calibrate the model with $\theta=2$ and obtain very similar results. All parameters are listed in Table 3.

Despite the simplicity of this model, it is worth noting that this calibration has a reasonably low share of credit-constrained firms ( $\pi=18$ percent) and that the mean debt-to-capital ratio $(\theta \pi=54$ percent) is in line with empirical findings (cf. Rajan and Zingales, 1995). Further, the parameterization produces a plausible cross-firm dispersion of TFP. With firm-level output equal to $y^{i}=\left(a^{i}-1\right) k^{i}+\left(A \ell^{i}\right)^{1-\alpha}\left(a^{i} k^{i}\right)^{\alpha}$, I calculate a standard deviation of $\log$ TFP equal to 0.33 , which is close to the within-industry average 0.39 reported in Bartelsman et al. (2013).

\subsection{Persistence of Sunspot Shocks}

For illustrative purposes, I first suppose that fundamental shocks are absent; that is, $\lambda_{t}$ and $A_{t}$ are at their steady-state values, while sunspot shocks are the only source of business cycle dynamics. In this case, the log-linearized dynamics of the credit-to-capital ratio 26 follows

$$
\hat{\theta}_{t+1}=\frac{1}{\varphi_{2}} \hat{\theta}_{t}+d_{1} \varepsilon_{t+1}^{s},
$$

where coefficients $d_{1}$ and $\varphi_{2}$ are constant terms and $\varepsilon_{t+1}^{s}$ is a sunspot shock. In particular, I find that the autocorrelation coefficient is

$$
\frac{1}{\varphi_{2}}=\frac{1}{\beta(1-\psi)+\beta \pi(1+\theta) \frac{a^{p}-a^{u}}{a^{u}}},
$$


Table 4

Model Statistics with Uncorrelated Sunspot Shocks

\begin{tabular}{|c|c|c|c|c|c|}
\hline & Output & Credit & Investment & Consumption & Employment \\
\hline \multicolumn{6}{|l|}{ U.S. data (1981-2012) } \\
\hline Relative volatility & 1 & 2.73 & 2.43 & 0.80 & 0.69 \\
\hline Autocorrelation & 0.848 & 0.832 & 0.618 & 0.899 & 0.893 \\
\hline Correlation with output & 1 & 0.620 & 0.715 & 0.969 & 0.910 \\
\hline \multicolumn{6}{|l|}{ Model } \\
\hline Relative volatility & 1 & 2.59 & 3.28 & 0.84 & 0.35 \\
\hline Autocorrelation & 0.925 & 0.903 & 0.791 & 0.978 & 0.978 \\
\hline Correlation with output & 1 & 0.993 & 0.771 & 0.923 & 0.923 \\
\hline \multicolumn{6}{|l|}{ SOURCE: Compustat. } \\
\hline \multicolumn{6}{|c|}{$\begin{array}{l}\text { NOTE: Output and investment are for the U.S. business sector. Credit is for the Compustat firm sample considered in } \\
\text { Section } 2 \text { without the largest } 1 \text { percent of firms. All variables are deflated, logged, and linearly detrended. Model statis- } \\
\text { tics are based on 100,000 simulations of } 32 \text { periods. The volatility of sunspot shocks is set so that the model-generated } \\
\text { output volatility matches the one in the data. }\end{array}$} \\
\hline
\end{tabular}

which equals 0.949 for the calibrated model parameters. That is, when I feed the model with uncorrelated sunspot shocks, the endogenous dynamics of credit are highly persistent, actually more so than in the data. $\underline{27}$ Table 4 confirms this finding and reports business cycle statistics under sunspot shocks. Most importantly, uncorrelated sunspot shocks generate persistent business cycle dynamics with autocorrelation coefficients that are somewhat above their data counterparts. Volatilities and comovement of consumption and investment are plausible, whereas credit is too strongly correlated with output, which comes as no surprise since all output dynamics are induced by the sunspot-driven dynamics of credit. $\underline{28}$

\subsection{Multiple Shocks}

To evaluate the relative importance of sunspot shocks for the overall business cycle dynamics, I include fundamental shocks to the financial sector (collateral parameter $\lambda_{t}$ ) as well as to the real sector (labor efficiency parameter $A_{t}$ ). I identify sunspot shocks as well as fundamental shocks as follows: I use the Compustat series for secured credit to compute the secured credit-to-capital ratio whose cyclical component measures $\hat{\theta}_{t}^{s}$. Similarly, all Compustat credit (secured and unsecured) identifies the series $\hat{\theta}_{t}$. I then use those two series to back out the (log deviations of) reputation values $\hat{v}_{t}$ and collateral parameters $\hat{\lambda}_{t}$. Labor efficiency $\hat{A}_{t}$ is identified so as to match the cyclical component of output. Hence, it picks up all output dynamics left unexplained by financial shocks (shocks to collateral $\hat{\lambda}$ and to unsecured credit $\hat{v}$ ). Therefore, all three shocks together generate by construction the output dynamics of the data. I can therefore measure how each one contributes to the total volatility and how it accounts for output movements in specific episodes.

I consider the following SVAR: 


$$
\left(\begin{array}{c}
\hat{A}_{t} \\
\hat{\lambda}_{t} \\
\hat{v}_{t}
\end{array}\right)=\mathbf{B}\left(\begin{array}{c}
\hat{A}_{t-1} \\
\hat{\lambda}_{t-1} \\
\hat{v}_{t-1}
\end{array}\right)+\left(\begin{array}{c}
e_{1 t} \\
e_{2 t} \\
e_{3 t}
\end{array}\right)
$$

with coefficient matrix $\mathbf{B}$, and apply the Choleski decomposition such that $\mathbf{e}=\left(e_{1 t}, e_{2 t}, e_{3 t}\right)=$ $\mathbf{C}\left(\varepsilon_{1 t}, \varepsilon_{2 t}, \varepsilon_{3 t}\right)$ with lower triangular matrix $\mathbf{C}$. I call $\varepsilon_{1 t}$ the technology shock, $\varepsilon_{2 t}$ the collateral shock, and $\varepsilon_{3 t}$ the sunspot shock. By ordering the sunspot shock as the last variable in the SVAR, I assume that those shocks can impact only credit market expectations contemporaneously, while all correlations in the innovations to $\left(\hat{A}_{t}, \hat{\lambda}_{t}, \hat{v}_{t}\right)$ are attributed to technology shocks and to collateral shocks. In other words, I may be attributing too much influence to technology and collateral shocks, thus providing a lower bound on the contribution of sunspot shocks. I take into account that the forward-looking equation for reputation values (11) imposes a restriction on the last row in equation (12). I therefore estimate only the first two equations and impose the model restriction on the last row in equation (12). $\underline{29}$

Figure 4 shows the implied time-series decomposition of output into the three components associated with the three identified structural shocks $\left(\varepsilon_{1 t}, \varepsilon_{2 t}, \varepsilon_{3 t}\right)$, where the solid line in each window represents the data output and the dashed line represents the predicted output when only one of the structural shocks is active. Panel D puts all three shocks together, which by construction explains all output variation. Sunspot shocks, $\varepsilon_{3 t}$, account for the broad business cycle features of output quite well (Panel C); this is despite the fact that I have attributed all the contemporaneous correlations of the three innovations to technology and collateral shocks. Collateral shocks seem to matter for the credit-expansion periods in the late 1990s and mid-2000s, while they only account for a moderate portion of the decline in 2007-09. Technology shocks do not appear to matter much for output movements since the 1990s, although they are responsible for a substantial fraction of the output drop after the Great Recession. $\cdot \underline{30}$

I can also decompose the total variance of output (more specifically, the power spectrum) into the three structural components, with each coming separately from one of the three identified shocks. I find that sunspot shocks account for 51 percent of the total output variance, collateral shocks account for 44 percent, and technology shocks account for only the remaining 5 percent. This result is quite striking: Even though the $\hat{A}_{t}$ series is constructed to match all output dynamics not explained by financial shocks, shocks to $\hat{A}_{t}$ play a rather minor role in the total output variance. This result-that the two financial shocks account for the vast majority of output dynamics—differs markedly from Jermann and Quadrini (2012), who find that productivity shocks and financial shocks both explain around half of output fluctuations. But the present model generates a similar result when I shut down sunspot shocks. Precisely, when I set $\hat{v}_{t}=0$ and identify $\hat{\lambda}_{t}$ and $\hat{A}_{t}$ to account for the dynamics of total firm credit and output, I find that structural shocks to collateral and to technology each account for around half of output volatility. Put differently, technology shocks pick up a large fraction of the output dynamics that come from the self-fulfilling belief shocks that drive unsecured credit in 


\section{Figure 4}

\section{Decomposition of Output for the Three Shocks}

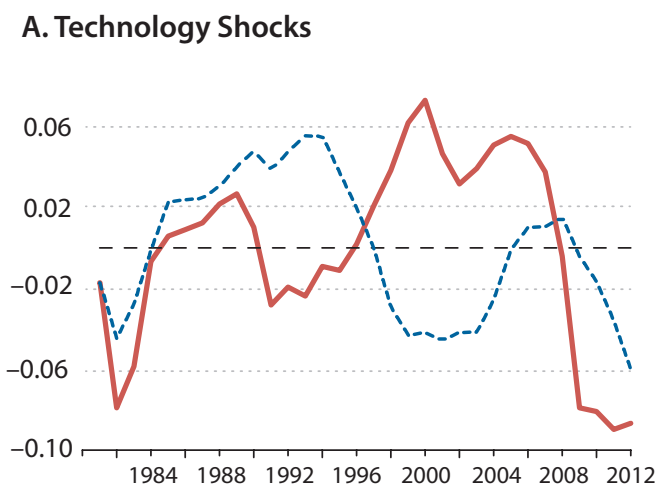

C. Sunspot Shocks

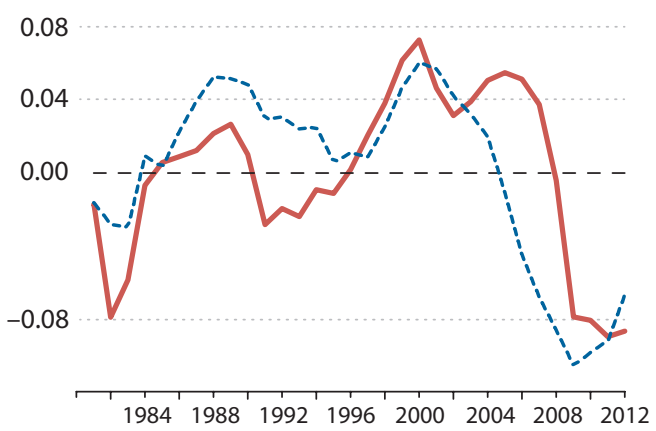

\section{B. Collateral Shocks}

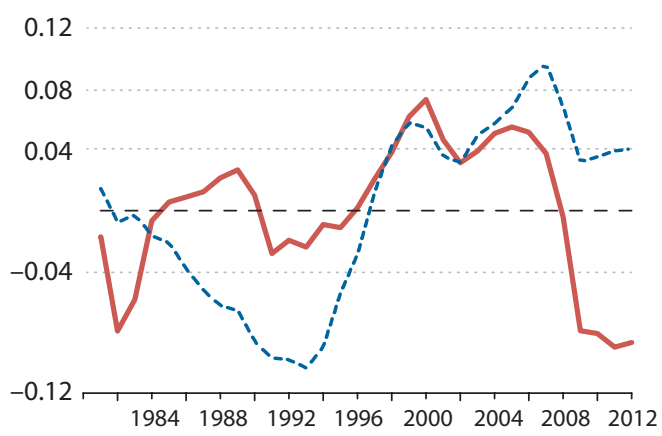

D. All Shocks

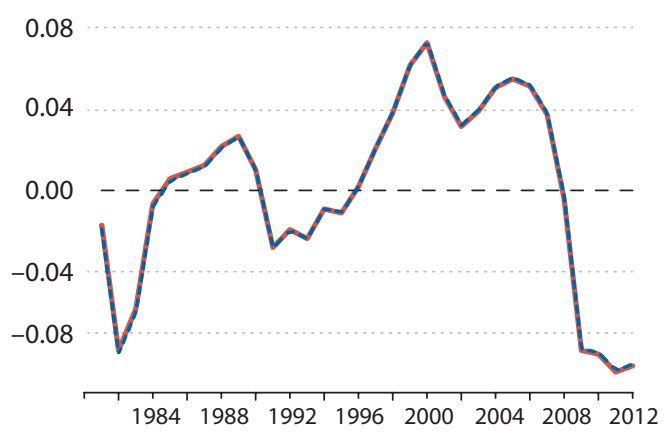

NOTE: In panel $A$ to $C$, the solid curves are data output and the dashed curves are model-generated output dynamics with only the designated shock active. In the bottom-right panel, all three shocks are active.

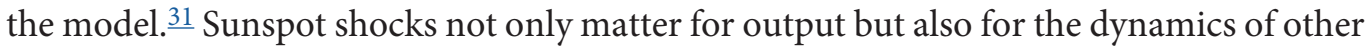
macroeconomic variables: In a variance decomposition, I find that sunspot shocks account for around 50 percent of the variance of employment, consumption, investment, and firm credit, whereas technology shocks account for less than 10 percent. $\underline{32}$

By construction, the three structural shocks not only describe output fluctuations but also the secured and unsecured credit dynamics. It is interesting to examine to what extent the three shocks contribute to these separate credit cycles and how these components relate to output dynamics. Sunspot shocks turn out to account for the major movements in unsecured credit, while technology shocks and collateral shocks do not capture the pattern of unsecured credit well. Given this finding and that unsecured credit is strongly procyclical, I can infer that sunspot shocks are the major driving force of the credit cycle.

Lastly, in Figure 5 I show the impulse responses of output, investment, consumption, and employment to the three orthogonal shocks (one standard deviation). Sunspot shocks generate a stronger and more persistent response than the other two shocks. In particular, a 


\section{Figure 5}

\section{Impulse Responses to the Three Shocks}

\section{A. Technology Shocks}

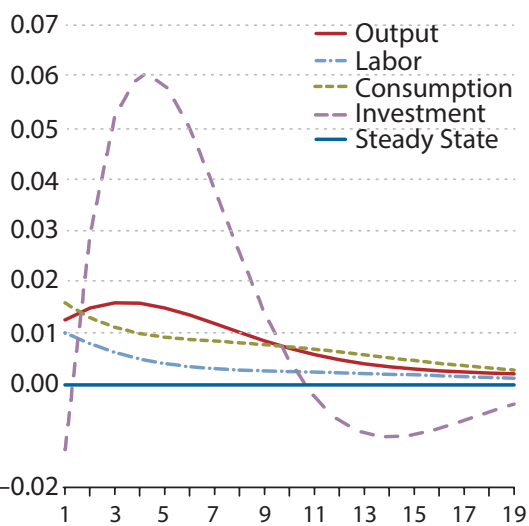

B. Collateral Shocks

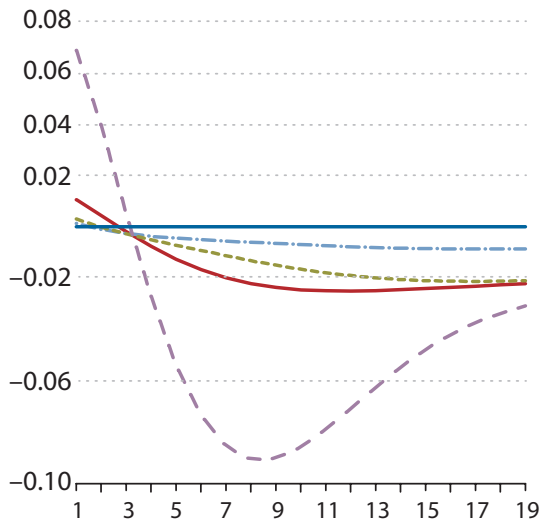

C. Sunspot Shocks

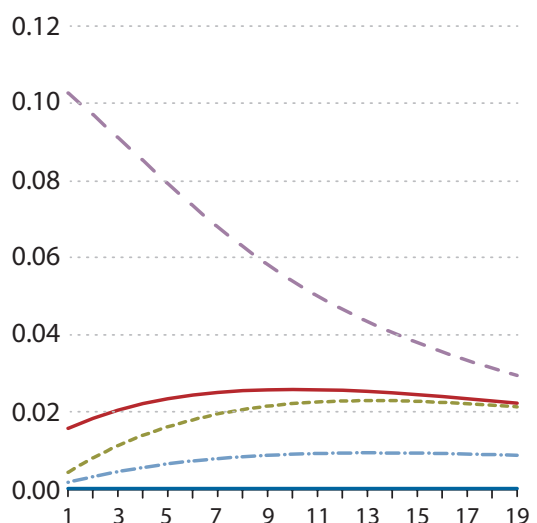

NOTE: In panel A to C, the solid curves are data output and the dashed curves are model-generated output dynamics with only the designated shock active. In the bottom-right panel, all three shocks are active.

collateral shock implies that the positive output response turns negative only two years after the shock, which is at odds with the vector autoregression evidence on the real effects of credit market shocks (e.g., Lown and Morgan, 2006, and Gilchrist et al., 2009). This suggests that sunspot shocks (on top of or independent of collateral shocks) are an important contributing factor.

\subsection{Autocorrelated Productivity}

A strong simplifying assumption in the benchmark model is that firm productivity is drawn each period independently from a two-point distribution. The main benefit is that this makes the model very tractable, permitting a complete analytical characterization of the global dynamics in Section 3. This framework can be readily extended to account for an autocorrelated idiosyncratic productivity process (still on a two-point distribution). All of the main results survive. In particular, there are multiple steady-state equilibria; further, a steady-state equilibrium with unsecured credit and some misallocation of capital is typically indeterminate and hence gives rise to sunspot-driven dynamics.

\section{CONCLUSIONS}

To study the role of unsecured firm debt, I develop and analyze a small dynamic general equilibrium model with heterogeneous firms and limited credit enforcement. In the model, credit constraints and aggregate productivity are endogenous variables. Constraints on unsecured credit depend on the value that borrowers attach to future credit market conditions, 
which is a forward-looking variable. Aggregate productivity depends on the reallocation of existing capital among heterogeneous firms which, among other things, depends on current credit constraints. When these constraints bind, they slow down capital reallocation between firms and push aggregate factor productivity below its frontier. I show that this model exhibits a very natural equilibrium indeterminacy that gives rise to endogenous cycles driven by selffulfilling beliefs in credit market conditions (sunspot shocks). In particular, a one-time sunspot shock triggers an endogenous and persistent response of credit, productivity, and output.

Cycles persist because of a dynamic complementarity in endogenous constraints on unsecured credit. Borrowers' incentives to default depend on their expectations of future credit market conditions, which in turn influence current credit constraints. If borrowers expect a credit tightening over the next few periods, their current default incentives become larger, which triggers a tightening of current credit. This insight also explains why a one-time sunspot shock must be followed by a long-lasting response of credit market conditions (and thus of macroeconomic outcomes): If market participants expect that a credit boom (or a credit slump) will die out quickly, these expectations could not be powerful enough to generate a sizable current credit boom (or slump).

\section{NOTES}

1 Other examples of financial shocks include the work of Kiyotaki and Moore (2012), who introduce shocks to asset resaleability, and Gertler and Karadi (2011), who consider shocks to the asset quality of financial intermediaries. These papers also impose or estimate highly persistent shock processes.

$\underline{2}$ The other determinate steady states of this model either do not sustain unsecured credit (and hence resemble similar dynamics as in a Kiyotaki-Moore-type model with binding collateral constraints) or they have an efficient allocation of capital (and hence exhibit the same business cycle properties as a frictionless real business cycle model).

$\underline{3}$ Although earlier work on indeterminacy has shown that sunspot shocks can induce persistent macroeconomic responses (e.g., Farmer and Guo, 1994, and Wen, 1998), the adjustment dynamics are typically sensitive to the particular specifications of technologies and preferences. In the model, persistent responses arise necessarily due to the dynamic complementarity in unsecured credit conditions.

$4 \mathrm{See}$, in particular, recent corporate finance contributions examining heterogeneity in the debt structure across firms (e.g., Rauh and Sufi, 2010; Giambona and Golec, 2012; and Colla et al., 2013). These do not address business cycles, however.

$\underline{5}$ This classification means that unsecured debt is not explicitly backed by collateral; it does not mean that it has zero (or little) recovery value in the case of default.

6 While the effect of the largest firms is also important for total debt growth, it is not important for its cyclicality. Total debt over this period grew much faster than GDP.

7 Firms in the Capital IQ sample are actually bigger than those in the Compustat samples. In the period 2002-12, the average asset size of firms in the full (bottom 99 percent, bottom 95 percent) Compustat sample is $\$ 2,602$ million ( $\$ 1,230$ million, $\$ 550$ million), whereas in the Capital IQ sample it is $\$ 3,391$ million ( $\$ 2,028$ million, $\$ 1,142$ million). In total, there are about twice as many observations in Compustat than in Capital IQ for each year.

8 Because the collateral requirement is a dummy variable, only a fraction of these loans might actually be secured by collateral. This measure of unsecured credit should therefore be regarded as a lower bound.

9 Note that the latter number is consistent with those found in two other studies about the debt structure of Compustat firms. Rauh and Sufi (2010) examine the financial footnotes of 305 randomly sampled non-financial firms in Compustat. Based on different measures, their unsecured debt share (defined as senior unsecured plus 


\section{Azariadis}

subordinated debt relative to total debt) is 70.3 percent. Giambona and Golec (2012) look at the distribution of unsecured debt shares for Compustat firms, reporting mean (median) values of $0.63(0.75)$.

10 Using bank survey data, Berger and Udell (1990) find that around 70 percent of all commercial and industrial loans in the United States are secured. Booth and Booth (2006) find that 75 percent of their sample of syndicated loans are secured.

11 I use a linear trend to capture the low-frequency movements in credit and output that are quite significant over the period 1981-2012.

12 The assumption of a representative owner by no means restricts this model to single-owner businesses. All it requires is that the firm's owners desire a smooth dividend stream, for which there is ample evidence (e.g., Leary and Michaely, 2011).

13 That is, lenders receive no payment in a default event. In the next section, I relax this assumption by introducing collateral assets and secured credit. In this extension, a fraction of unsecured borrowing can also be recovered.

14 We can think of such default events as either a liquidation, in which case the firm owners can start a new firm that needs to build up a reputation, or as a reorganization, in which case the firm continues operation.

15 With permanent exclusion of defaulters $(\psi=0)$, this enforcement technology corresponds to the one discussed by Bulow and Rogoff (1989) and Hellwig and Lorenzoni (2009), who assume that defaulters are excluded from future credit but are still allowed to save.

16 Outside the steady state, the workers' first-order condition $\mathbb{E}_{t}\left[\beta R_{t} w_{t} / w_{t+1}\right]<1$ is satisfied in the log-linear approximation of the model for the calibrated parameters and for shocks of reasonable magnitude.

17 If productivity shocks are autocorrelated, the wealth distribution becomes a state variable, but the model remains tractable since only a single variable, the wealth share of borrowing firms, matters for aggregate dynamics. This follows again because linear policy functions permit aggregation.

18 In the absence of sunspot shocks, the expectations operator could be dropped from this and from subsequent equations because I abstract from aggregate shocks to economic fundamentals in this section.

19 In the first-best equilibrium of this economy, there are no credit constraints; the interest rate equals the capital return of productive firms, $R_{t}=a^{p} R_{t}^{*}$, so all firms (productive and unproductive) earn the same return. All capital is employed at productive firms, and the model is thus isomorphic to a standard growth model with a representative firm.

$\underline{20}$ In endowment economies with permanent exclusion of defaulters, it is well-known that perfect risk sharing can be implemented if the discount factor is sufficiently large, if risk aversion is sufficiently strong, or if the endowment gap between agents is large enough (see, e.g., Kehoe and Levine, 2001). Azariadis and Kaas (2013) show that the role of the discount factor changes decisively if market exclusion is temporary. Note that the multiplicity results discussed in this article do not change under permanent exclusion of defaulters.

21 As in the simpler model of the previous section, the other (determinate) steady states either feature efficient factor allocations or do not sustain unsecured credit. Hence, their business cycle properties either resemble those of a standard frictionless model or those of an economy with collateral-based credit constraints.

$\underline{22}$ Output is real value added in the business sector, and the capital stock is obtained from the perpetual inventory method based on total capital expenditures in the business sector. This yields 1.49 as the target for the capitaloutput ratio.

$\underline{23}$ This 10-year default flag corresponds to the bankruptcy regulation for individual firm owners who file for bankruptcy under Chapter 7 of the U.S. Bankruptcy Code. Generally, business firms in the United States can file for bankruptcy under either Chapter 7 (which leads to liquidation) or Chapter 11 (which allows continued operation after reorganization). In either case, it is plausible to assume that the reputation loss from default inhibits full access to credit for an extended period.

24 The normalization $a=a^{u}+\pi(1+\theta)\left(a^{p}-a^{u}\right)=1$ then yields parameters $a^{p}$ and $\gamma=a^{u} / a^{p}$.

$\underline{25}$ Regarding (i), credit market liabilities of non-financial business are 0.82 of annual output (averaged over 1981-2012, flow-of-funds accounts of the Board of Governors of the Federal Reserve System, Z.1, Table L.101). Regarding (ii), debt-to-equity ratios below 3 are usually required to qualify for commercial loans (see Herranz et al., 2017). Further, in the SSBF (Capital IQ, Compustat) samples, the mean debt-to-equity ratios are $3.04(3.15,2.43)$. 
$\underline{26}$ The hat symbol over a variable indicates the log deviation of that variable from the steady state. The credit-tocapital ratio in the model is $\theta_{t} \pi$, for which the log deviation equals that of the borrowers' credit-equity ratio $\theta_{t^{\prime}}$ because $\pi$ is constant.

27 To obtain data analogs for the (linearly detrended) credit-to-capital ratio, I can either use firm credit from the flow-of-funds accounts or from Compustat, which yield annual autocorrelation coefficients of 0.883 (flow of funds) and 0.817 (Compustat).

28 When I decompose total credit into secured and unsecured components, I find that both are strongly procyclical when sunspots are the only source of shocks; correlations with output are 0.83 (0.95) for secured (unsecured) credit. Secured credit is however much less volatile; relative standard deviations are 1.36 (4.13) for secured (unsecured) credit.

$\underline{29}$ I also perform a similar analysis in which I estimate equation (12) without any restrictions on matrix $\mathbf{B}$. The main findings are similar and attribute an even larger role to sunspot shocks. Particularly, I find that sunspot shocks account for around 70 percent of the variance of output, employment, consumption, and investment. They also induce similarly persistent impulse responses.

$\underline{30}$ Somewhat surprisingly, Panel A of Figure 4 shows a negative correlation between detrended GDP and technology shocks over the period of the "Great Moderation," roughly 1988-2008. One possible explanation is that credit markets improved markedly over this period, reducing capital misallocation and boosting the effective rate of capital utilization by too big a margin relative to observed GDP growth. A drop in TFP would then exactly match GDP with the Solow residual of a model with full capital utilization. Cette et al. (2016) list some evidence favoring slower TFP growth since the millennium.

31 The model further differs from Jermann and Quadrini (2012) in that aggregate productivity is partly endogenous and hence correlates positively with financial conditions.

32 The standard errors for these point estimates are small. For example, the one-standard-error bands for the sunspot contributions of any of these variables are between 1- and 11-percentage-points wide.

\section{REFERENCES}

Alvarez, Fernando and Jermann, Urban. "Efficiency, Equilibrium, and Asset Pricing with Risk of Default." Econometrica, July 2000, 68(4), pp. 775-97; https://doi.org/10.1111/1468-0262.00137.

Azariadis, Costas and Kaas, Leo. "Endogenous Credit Limits with Small Default Costs." Journal of Economic Theory, March 2013, 148(2), pp. 806-24; https://doi.org/10.1016/j.jet.2012.08.004.

Azariadis, Costas and Kaas, Leo. "Capital Misallocation and Aggregate Factor Productivity." Macroeconomic Dynamics, March 2016, 20(2), pp. 525-43; https://doi.org/10.1017/S1365100514000236.

Azariadis, Costas; Kaas, Leo and Wen, Yi. "Self-Fulfilling Credit Cycles." Review of Economic Studies, October 2016, 83(4), pp. 1364-405; https://doi.org/10.1093/restud/rdv056.

Bartelsman, Eric; Haltiwanger, John and Scarpetta, Stefano. “Cross-Country Difference in Productivity: The Role of Allocation and Selection." American Economic Review, February 2013, 103(1), pp. 305-34; https://doi.org/10.1257/aer.103.1.305.

Benhabib, Jess and Farmer, Roger. "Indeterminacy and Increasing Returns." Journal of Economic Theory, June 1994, 63(1), pp. 19-41; https://doi.org/10.1006/jeth.1994.1031.

Benhabib, Jess and Farmer, Roger. "Indeterminacy and Sunspots in Macroeconomics," in J.B. Taylor and Michael Woodford, eds., Handbook of Macroeconomics. Volume 1A. Amsterdam: North-Holland, 1999, pp. 387-448; https://doi.org/10.1016/S1574-0048(99)01009-5.

Benhabib, Jess and Wang, Pengfei. "Financial Constraints, Endogenous Markups, and Self-fulfilling Equilibria." Journal of Monetary Economics, October 2013, 60(7), pp. 789-805; https://doi.org/10.1016/j.jmoneco.2013.06.004.

Berger, Allen and Udell, Gregory. "Collateral, Loan Quality and Bank Risk." Journal of Monetary Economics, 1990, 25(1), pp. 21-42; https://doi.org/10.1016/0304-3932(90)90042-3. 


\section{Azariadis}

Bernanke, Ben S. and Gertler, Mark. "Agency Costs, Net Worth, and Business Fluctuations." American Economic Review, March 1989, 79(1), pp. 14-31; https://www.jstor.org/stable/1804770?seq=1\#page scan tab contents.

Booth, James R. and Booth, Lena Chua. "Loan Collateral Decisions and Corporate Borrowing Costs." Journal of Money, Credit and Banking, February 2006, 38(1), pp. 67-90; https://doi.org/10.1353/mcb.2006.0011.

Bulow, Jeremy and Rogoff, Kenneth. "Sovereign Debt: Is to Forgive to Forget?" American Economic Review, March 1989, 79(1), pp. 43-50; https://www.jstor.org/stable/1804772?seq=1\#page_scan tab contents.

Caballero, Ricardo, J. and Krishnamurthy, Arvind. "Bubbles and Capital Flow Volatility: Causes and Risk Management." Journal of Monetary Economics, 2006, 53(1), pp. 35-53; https://doi.org/10.1016/j.jmoneco.2005.10.005.

Cette, Gilbert; Fernald, John G. and Mojon, Benoit. "The Pre-Great Recession Slowdown in Productivity." European Economic Review, September 2016, 88, pp. 3-20; https://doi.org/10.1016/j.euroecorev.2016.03.012.

Colla, Paolo; Ippolito, Filippo and Li, Kai. “Debt Specialization." Journal of Finance, October 2013, 68(5), pp. 2117-41; https://doi.org/10.1111/jofi.12052.

Farhi, Emmanuel and Tirole, Jean. "Bubbly Liquidity." Review of Economic Studies, 2012, 79(2), pp. 678-706; https://doi.org/10.1093/restud/rdr039.

Farmer, Roger and Guo, Jang-Ting. "Real Business Cycles and the Animal Spirits Hypothesis." Journal of Economic Theory, June 1994, 63(1), pp. 42-72; https://doi.org/10.1006/jeth.1994.1032.

Garriga, Carlos; Kydland, Finn E. and Sustek, Roman. "Nominal Rigidities in Debt and Product Markets." Working Paper 2016-017A, Federal Reserve Bank of Saint Louis, 2016; https://research.stlouisfed.org/wp/2016/2016-017.pdf.

Gertler, Mark and Karadi, Peter. "A Model of Unconventional Monetary Policy." Journal of Monetary Economics, January 2011, 58(1), pp. 17-34; https://doi.org/10.1016/j.jmoneco.2010.10.004.

Giambona, Erasmo and Golec, Joseph. "The Growth Opportunity Channel of Debt Structure." Working paper, Amsterdam Business School Research Institute, 2013; http://hdl.handle.net/11245/1.408704.

Gilchrist, Simon; Yankov, Vladimir and Zakrajsek, Egon. "Credit Market Shocks and Economic Fluctuations: Evidence from Corporate Bond and Stock Markets." Journal of Monetary Economics, April 2009, 56(4), pp. 471-93; https://doi.org/10.1016/j.jmoneco.2009.03.017.

Gu, Chao; Mattesini, Fabrizio; Monnet, Cyril and Wright, Randall. "Endogenous Credit Cycles." Journal of Political Economy, October 2013, 121(5), pp. 940-65; https://doi.org/10.1086/673472.

Harrison, Sharon G. and Weder, Mark. "Sunspots and Credit Frictions." Macroeconomic Dynamics, July 2013, 17(5), pp. 1055-69; https://doi.org/10.1017/S1365100511000836.

Hellwig, Christian and Lorenzoni, Guido. “Bubbles and Self-Enforcing Debt." Econometrica, July 2009, 77(4), pp. 1137-64; https://doi.org/10.3982/ECTA6754.

Herranz, Neus; Krasa, Stefan and Villamil, Anne. "Entrepreneurs, Legal Institutions and Firm Dynamics." Economic Theory, January 2017, 63(1), pp. 263-85; https://doi.org/10.1007/s00199-016-1026-8.

Jermann, Urban and Quadrini, Vincenzo. "Macroeconomic Effects of Financial Shocks." American Economic Review February 2012, 102(1), pp. 238-71; https://doi.org/10.1257/aer.102.1.238.

Kehoe, Timothy and Levine, David. "Debt-Constrained Asset Markets." Review of Economic Studies, October 1993, 60(4), pp. 865-88; https://doi.org/10.2307/2298103.

Kehoe, Timothy and Levine, David. "Liquidity Constrained Markets Versus Debt Constrained Markets." Econometrica, May 2001, 69(3), pp. 575-98; https://doi.org/10.1111/1468-0262.00206.

Kiyotaki, Nobuhiro and Moore, John. "Credit Cycles." Journal of Political Economy, April 1997, 105(2), pp. 211-48; https://doi.org/10.1086/262072.

Kiyotaki, Nobuhiro and Moore, John. "Liquidity, Business Cycles, and Monetary Policy." NBER Working Paper No. 17934, National Bureau of Economic Research, March 2012; http://www.nber.org/papers/w17934.

Kocherlakota, Narayana. "Bursting Bubbles: Consequences and Cures." Paper presented at the Macroeconomic and Policy Challenges Following Financial Meltdowns Conference, Federal Reserve Bank of Minneapolis, April 2009; https://www.imf.org/external/np/seminars/eng/2009/macro/pdf/nk.pdf. 
Leary, Mark T. and Michaely, Roni. "Determinants of Dividend Smoothing: Empirical Evidence." Review of Financial Studies, October 2011, 24(10), pp. 3197-249; https://doi.org/10.1093/rfs/hhr072.

Liu, Zheng and Wang, Pengfei. "Credit Constraints and Self-Fulfilling Business Cycles." American Economic Journal: Macroeconomics, January 2014, 6(1), pp. 32-69; https://doi.org/10.1257/mac.6.1.32.

Lown, Cara and Morgan, Donald. "The Credit Cycle and the Business Cycle: New Findings Using the Loan Officer Opinion Survey." Journal of Money, Credit and Banking, September 2006, 38(6), pp. 1575-97; https://doi.org/10.1353/mcb.2006.0086.

Miao, Jianjun and Wang, Pengfei. "Banking Bubbles and Financial Crises." Journal of Economic Theory, May 2015, 157(5), pp. 763-92; https://doi.org/10.1016/j.jet.2015.02.004.

Rajan, Raghuram G. and Zingales, Luigi. "What Do We Know About Capital Structure? Some Evidence from International Data." Journal of Finance, December 1995, 50(5), pp. 1421-60; https://doi.org/10.1111/j.1540-6261.1995.tb05184.x.

Rauh, Joshua D. and Sufi, Amir. "Capital Structure and Debt Structure." Review of Financial Studies, October 2010, 23(12), pp. 4242-80; https://doi.org/10.1093/rfs/hhq095.

Wen, Yi. "Capacity Utilization Under Increasing Return to Scale." Journal of Economic Theory, July 1998, 81(1), pp. 7-36; https://doi.org/10.1006/jeth.1998.2412.

Woodford, Michael. "Stationary Sunspot Equilibria in a Finance-Constrained Economy." Journal of Economic Theory, October 1986, 40(1), pp. 128-37; https://doi.org/10.1016/0022-0531(86)90011-6. 
